\title{
Evaluation of thickness estimation techniques in seismically thin beds
}

\section{Evaluación de técnicas de estimación del espesor en estratos sísmicamente delgados}

Fecha de entrega: 31 de enero 2020

Fecha de aceptación: 3 de septiembre 2020

\section{Valentina Ortiz Bustos ${ }^{1}$, Rodrigo Abarca-del-Río ${ }^{2}$, Arturo Belmonte-Pool ${ }^{2}$ and Matthew Miller ${ }^{2}$}

${ }^{1}$ Departamento de Ingeniería Mecánica, Facultad de Ingeniería, Universidad de Magallanes, Av. Bulnes 01855, Punta Arenas, Chile, valeortizbustos@gmail.com

${ }^{2}$ Departamento de Geofísica, Facultad de Ciencias Físicas y Matemáticas, Universidad de Concepción, Av. Esteban Iturra s/n, Casilla 160-C, Concepción, Chile, roabarca@udec.cl (Orcid: 0000-0002-2724-7754), abelmonte@dgeo.udec.cl, mmiller@dgeo.udec.cl

The quantitative estimation of rock strata thickness below the vertical seismic resolution limit is a great challenge for seismic exploration. Most previous studies are focused on thin layers interspersed within an infinite homogeneous rock which does not exhibit interference effects due to the presence of other rock strata. These cases are not representative of most real-life situations, so their results cannot be considered to be general. In this paper we experimentally evaluate the use of the peak instantaneous frequency, dominant frequency, and spectral decomposition attributes in the quantification of thin layers by using two simple isolated-layer wedge models and a third multilayer wedge model which simulates a stratified formation. We conclude that, in the presence of interference, only spectral decomposition would allow us to estimate the thickness of a thin layer, and even the thicker ones. However, its relationship with layer thickness is inverted when varying the elastic properties of the formation under evaluation, so this attribute should only be used in rock strata whose elastic properties remain approximately constant.

Keywords: seismic thickness, tuning, thin beds, peak instantaneous frecuency, peak spectral frecuency, spectral decomposition
La estimación cuantitativa de un estrato de roca bajo el límite de resolución sísmica vertical es un gran desafio para la exploración sísmica. La mayoría de los estudios se centran en capas delgadas intercaladas en una roca homogénea infinita, la cual no presenta efectos de interferencia desde otros estratos de roca. Estos casos no son representativos de la mayoría de las situaciones reales, por lo cual sus resultados no pueden considerarse generales. En este artículo se evalúa experimentalmente la utilización de los atributos peak de frecuencia instantánea, frecuencia dominante, y descomposición espectral en la cuantificación de capas delgadas mediante dos sencillos modelos de cuña de capa aislada y un tercer modelo de cuña multicapa, el cual, simula una formación estratificada. Concluyendo que bajo la presencia de interferencia, solo la descomposición espectral nos permitirá estimar el espesor de una capa delgada, incluso de capas gruesas. Sin embargo, su relación con el espesor se invierte al variar las propiedades elásticas de la formación evaluada, por lo cual, este atributo sólo debe ser utilizado en estratos de roca cuyos propiedades elásticas se mantengan aproximadamente constantes.

Palabras clave: espesor sísmico, tuning, estratos delgados, peak de frecuencia instantánea, frecuencia espectral máxima, descomposición espectral

\section{Introduction}

Seismically-thin layer reservoirs $^{1}$ are one of the most important targets in the exploration and exploitation of

${ }^{1}$ thinner than $\lambda / 4$, where $\lambda$ corresponds to the dominant wavelength hydrocarbons, but their identification, and the quantitative estimation of their thickness, is always a great challenge (Sun et al., 2009). Above the vertical seismic resolution threshold, the quantitative estimation of layer thickness is made from the apparent thickness measurement (Kallweit and Wood, 1982), but in seismically-thin layers this 
interval apparently stabilizes or decays as a result of the interference between the reflections from the top and the base of the rock stratum, a phenomenon known as the tuning effect. This phenomenon commonly occurs when a downgoing wave is reflected by multiple slightlyspaced interfaces. If the resulting upward reflections are superimposed, the reflected seismic energy will be altered and this interference changes the amplitude of the real geological response (Hamlyn, 2014).

Widess (1973) established that the detectable limit of thickness for an insolated layer corresponds to $\lambda / 8$, but, in practice, $\lambda / 4$ is usually considered as the limit of vertical seismic resolution in real rock strata, taking into account the influence of noise and the wavelet (Sun et al., 2009).

Below the vertical seismic resolution limit, Widess (1973) showed that it is possible to quantitatively estimate, from the linear relationship between thickness and the reflection amplitude, the thickness of a thin layer in reservoirs formed by a thin layer of rock interspersed in an infinite homogeneous rock.

However, this technique is error-prone and highly dependent on the magnitude and phase determination of the reflection (Partyka et al., 1999). Partyka et al. (1999) proposed a novel method to delineate the temporal thickness of a rock stratum and the geological discontinuities, by transforming the seismic data to the frequency domain, through the Fourier transform, in a more robust and phase-independent approach than the pioneering method developed by Widess (1973). Marfurt and Kirlin (2001), using an extension of the algorithm presented by Partyka et al. (1999), developed a set of attributes that permits a rapid quantification of the thickness of a thin layer. Liu and Marfurt (2006) determined experimentally that the thickness of a thin bed can be quantified by the instantaneous frequency peak attribute.

However, the cases considered by Widess (1973), Partyka et al. (1999), Marfurt and Kirlin (2001) and Liu and Marfurt (2006) are not representative of most real situations, because they only consider isolated rock strata, i.e. rock layers that do not present interference effects from other strata. Therefore, their results and conclusions cannot be considered to be general.

In order to observe and assess the different methodologies in rock strata that present interference effects from other rock layers, this article evaluates the techniques to quantify the thickness of seismically thin layers proposed by Partyka et al. (1999), Marfurt and Kirlin (2001) and Liu and Marfurt (2006), using two simple wedge models and a third multilayer model, which simulates a stratified reservoir made up of several rock layers.

\section{Spectral decomposition}

Spectral decomposition is the representation or analysis of a seismic trace in the frequency and time domain. Timefrequency analysis, resulting from spectral decomposition, is the superposition of the wavelet spectra that occur as a function in time (Castagna et al., 2003).

Partyka et al. (1999) and Partyka (2005), demonstrated the interpretative application of spectral decomposition in the characterization of a reservoir. The basic concept behind this technique is that seismic reflections from a thin layer have a characteristic expression in the frequency domain that is indicative of the temporal thickness of the layer. In this way, the thickness of a rock layer can be obtained from the amplitudes extracted from the discrete Fourier components.

The value of the frequency component determines the period of nodes in the amplitude spectrum with respect to the thickness of a thin layer, in the form:

$$
P_{t}=\frac{1}{f}
$$

where $P_{t}$ corresponds to the period of nodes in the amplitude spectrum with respect to the temporal thickness, and $f$ represents the discrete Fourier frequency. Each thickness/ velocity/frequency combination exhibits a characteristic relationship in the frequency spectrum. By choosing appropriately-low frequency components, the entire range of possible thicknesses is forced under the tuning thickness $(\lambda / 4)$, and therefore can be quantified using only the variability of the amplitude spectrum.

\section{Dominant frequency}

Marfurt and Kirlin (2001) developed an attribute that allows the simplification of the information provided by the spectral decomposition, the spectral frequency peak or dominant frequency. The spectral frequency peak is extracted from the spectrally-decomposed seismic data 
and corresponds to the frequency, $f$, at which the amplitude $a_{j}(f, t)$, defined as:

$$
a_{j}(f, t)=\left[u_{j}^{2}(f, t)+v_{j}^{2}(f, t)\right]^{1 / 2}
$$

is maximum (Marfurt and Kirlin, 2001). This attribute, which captures the essence of the spectrum as a result of the intonation of the thin layers, is inversely related to the thickness of the rock layer, where low tuning frequencies will illuminate the thicker layers, and high tuning frequencies will highlight the thinner layers. However, in the same way as for the spectral decomposition method, the thickness estimate from the dominant frequency is limited by the seismic bandwidth (Partyka, 2001).

\section{Instantaneous frequency peak}

Instantaneous frequency is one of the basic seismic attributes derived from a seismic trace. The seismic trace can be considered as the real component of a complex trace, whose imaginary component can be generated by using the Hilbert transform. If $x(t)$ is a seismic trace and $y(t)$ is its Hilbert transform, then the complex trace is defined as:

$$
z(t)=x(t)+i y(t)=R(t) e^{i \theta(t)}
$$

where $R(t)$ denotes the instantaneous amplitude and $\theta(t)$ corresponds to the instantaneous phase. The instantaneous frequency is defined as:

$$
f(t)=\frac{1}{2 \pi} \frac{d \theta(t)}{d t}
$$

\section{(Taner et al., 1979; Zeng, 2010).}

The advantage of considering a seismic section as the real part of a complex function is that the seismic signal is decomposed into functions that distinguish the amplitude information of the original trace from the angular amplitude, phase and frequency information (Robertson and Nogami, 1984).

Liu and Marfurt (2006) proposed the use of the instantaneous frequency peak to quantify thickness, demonstrating experimentally (from a simple wedge model) that the instantaneous frequency peak, calculated in a small window around the thin layer response, has an inverse linear relationship with thickness (Liu and Marfurt, 2006).

\section{Wedge models}

In order to visualize, illustrate and compare how the above attributes relate to the thickness of a seismically thin layer, three models are constructed. Two models are of an isolated wedge layer, whose thickness varies from 0 to 65 $\mathrm{m}$, interspersed between two rock layers. The first model, defined as Type I (according to Chung and Lawton, 1995), is constituted in such a way that the coefficients of reflection from the layer top and base present equal magnitude and opposite polarity. The second model, defined as Type IV, is constructed so that these reflection coefficients are of equal magnitude and equal polarity.

And a third multilayer wedge model simulates a stratified reservoir, similar to the Type I model but with two thin layers of porous sand attached above and below the wedge. The models are presented in Figure 1, the speeds and densities considered in each case are described in Table 1.

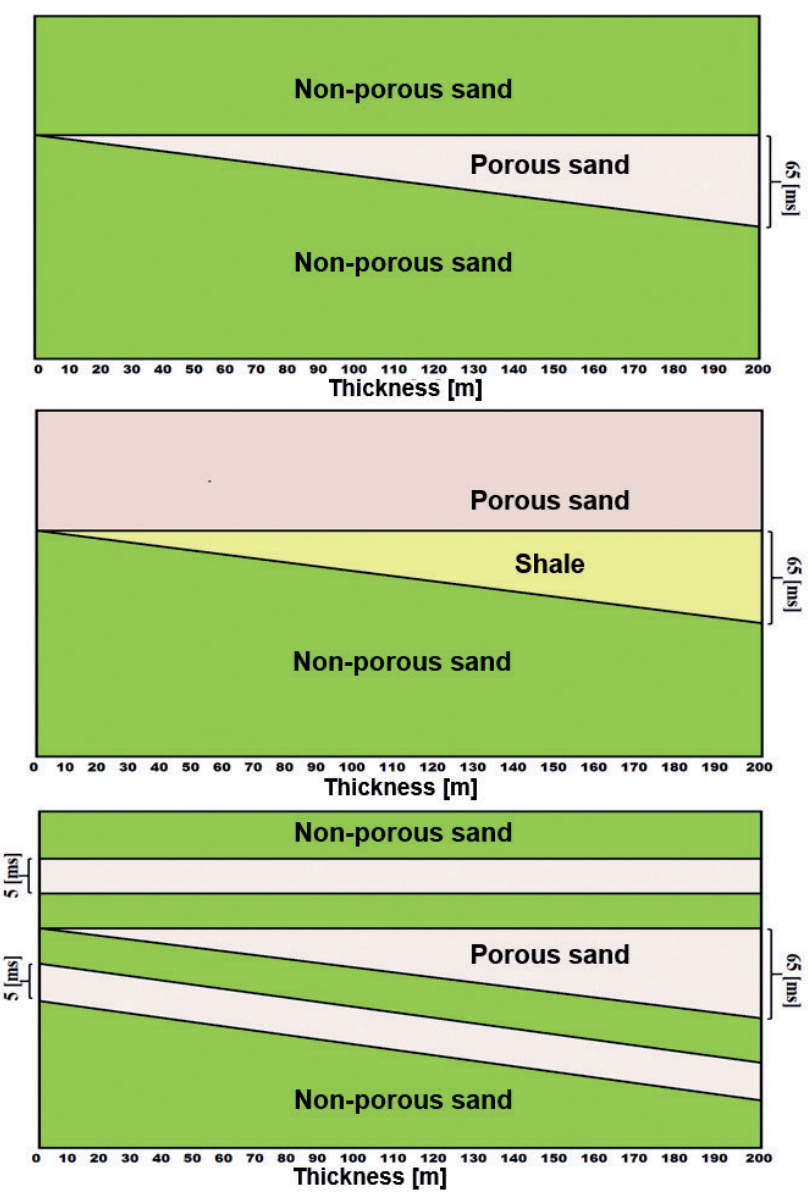

Figure 1: Different wedge models used to evaluate the different methods for estimating thickness in thin layers (top) type I wedge model, (middle) type IV wedge model, (bottom) multilayer wedge model, consisting of three layers of porous sand interspersed with non-porous sand. 
Table 1: Lithologies, velocities and densities of the rock layers representing the fundamental reflective series I and IV.

\begin{tabular}{|l|c|c|}
\hline Reflective series I IV & I & IV \\
\hline Top layer & Non-porous sand & Porous sand \\
V1, $\mathrm{m} / \mathrm{s}-\rho_{1}, \mathrm{~kg} / \mathrm{m}^{3}$ & $4270-2505$ & $3050-2303$ \\
\hline Intermediate layer & Porous sand & Shale \\
V2, $\mathrm{m} / \mathrm{s}-\rho_{2}, \mathrm{~kg} / \mathrm{m}^{3}$ & $3050-2303$ & $3350-2359$ \\
\hline Bottom layer & Non-porous sand & Non-porous sand \\
V3, $\mathrm{m} / \mathrm{s}-\rho_{3}, \mathrm{~kg} / \mathrm{m}^{3}$ & $4270-2505$ & $4270-2505$ \\
\hline
\end{tabular}

a)

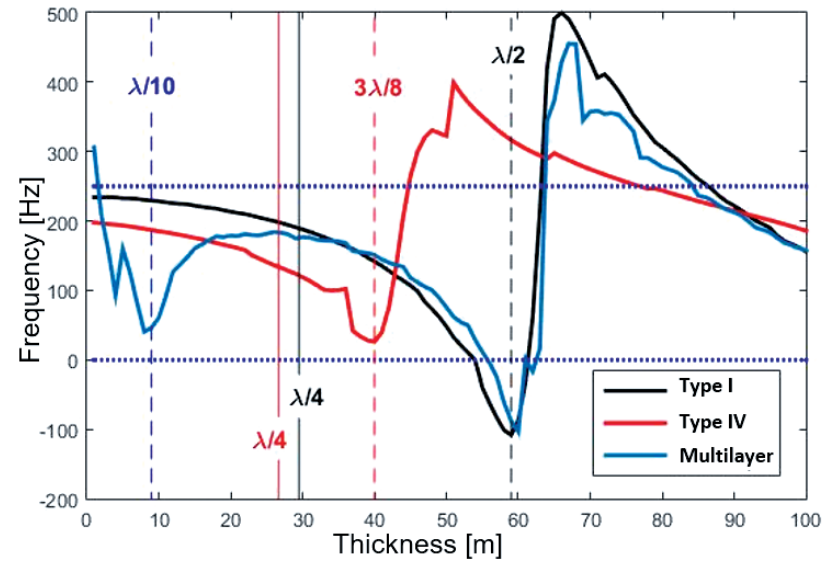

b)

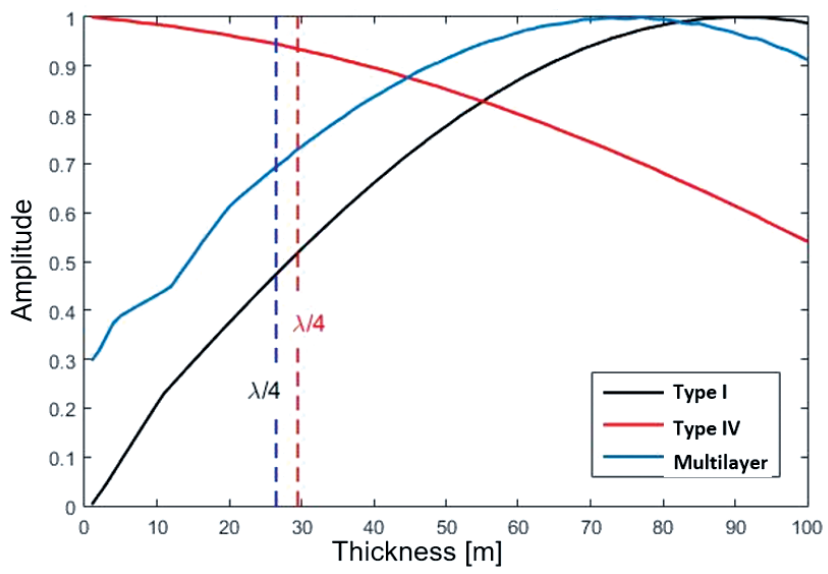

c)

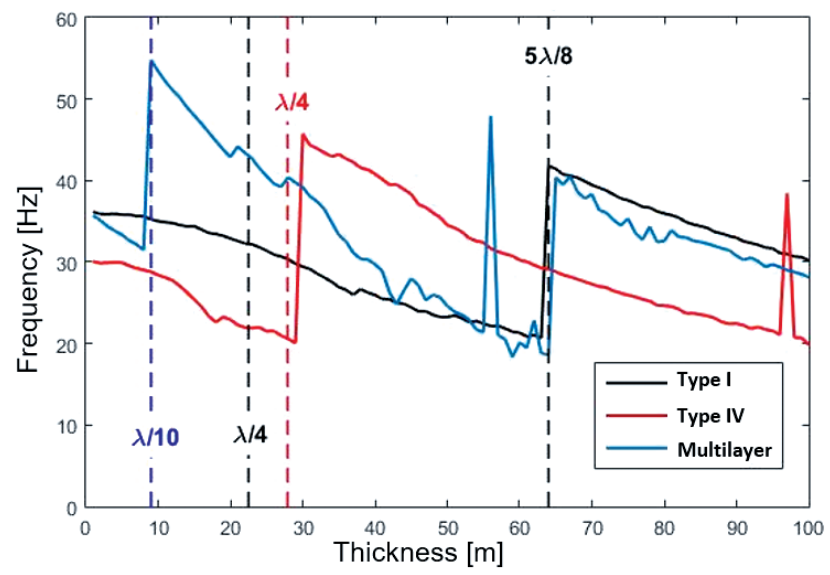

Figure 2: Attribute behaviour: (a) instantaneous frequency peak, (b) spectral magnitude and (c) spectral frequency peak as a function of wedge thickness, evaluated in the centre of the model. For the reflective series Type I (black), Type IV (red) and Multilayer (blue).
Figure 2 shows the responses of the instantaneous frequency peak, spectral decomposition and spectral frequency peak, as a function of the thickness of the rock stratum, for the three wedge models evaluated. By comparing Figures 2a and $2 \mathrm{c}$, it is possible to appreciate that the instantaneous frequency peak and spectral frequency peak attributes are inversely related to the thickness for the isolated layer models (Types I and IV). This shows that, for isolated seismically thin layers, both attributes can provide a good estimate of the thickness of the reservoir studied. However, for the multilayer wedge model both attributes are related in a non-linear way to thickness, even for thin layers (lower than $\lambda / 4$ ). This shows that for cases where the reservoir displays interference effects from other thin layers, it is not possible to quantify the thickness by using the instantaneous frequency peak and spectral frequency peak attributes. In contrast, the amplitude spectrum of an appropriately-low frequency component (as presented in Figure $2 b$ ) is linearly related to the thickness for all three cases evaluated, allowing the thickness to be quantified even in thick layers. But their relationship is reversed as the acoustic properties of the evaluated rock strata vary.

\section{Application to field data}

The instantaneous frequency peak, spectral decomposition and spectral frequency peak attributes are evaluated in the Lower Glauconitic Zone formation, in the northern sector of the Primavera commune, located in Tierra del Fuego, Chile (see Figure 3). The formation extends across the evaluated area, and presents thicknesses, decreasing towards the northeast, that are at the limit of vertical seismic resolution. These attributes are then compared to 60 well logs, distributed throughout this area.
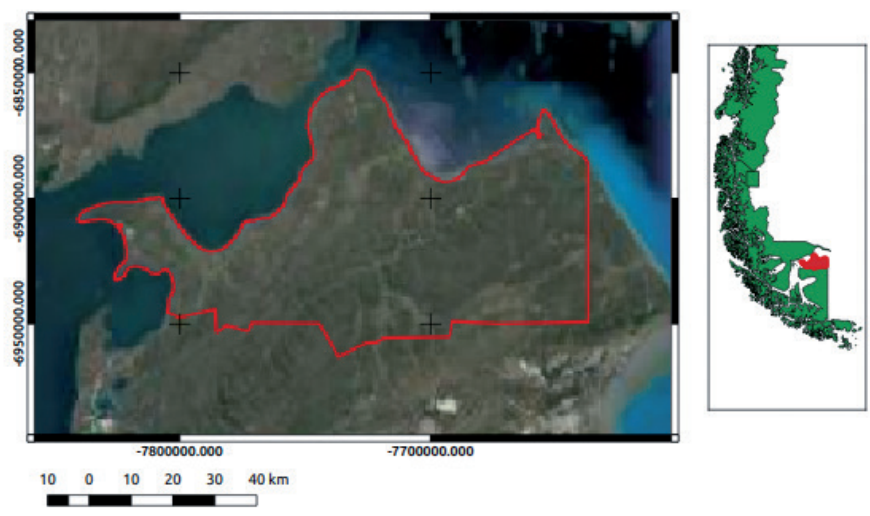

Figure 3: Location of the evaluated area, corresponding to the northern sector of the commune of Primavera, Tierra del Fuego, Chile. 
Ortiz, V., Abarca-del-Río, R., Belmonte-Pool, A. and Miller, M. (2020). Evaluation of thickness estimation techniques in seismically thin beds. Obras y Proyectos 28, 6-11

a)

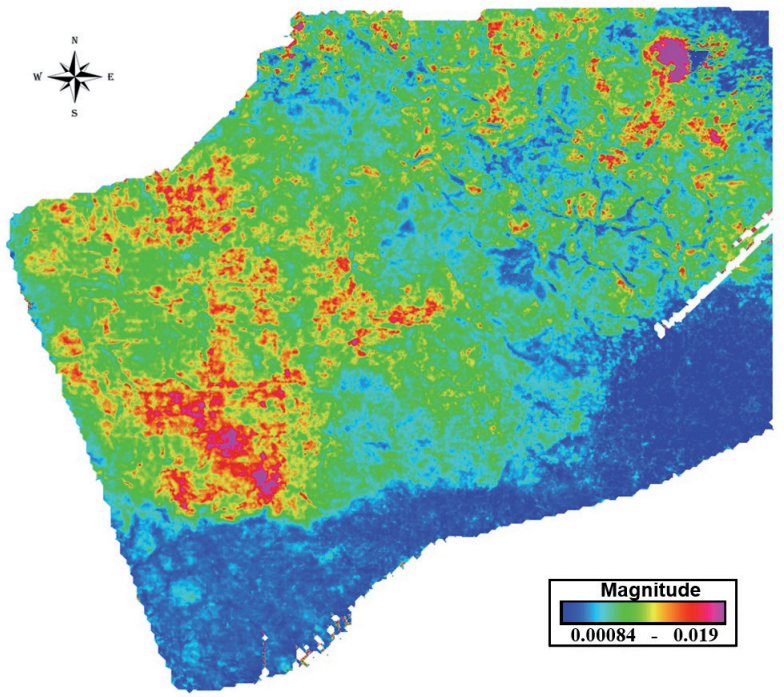

b)

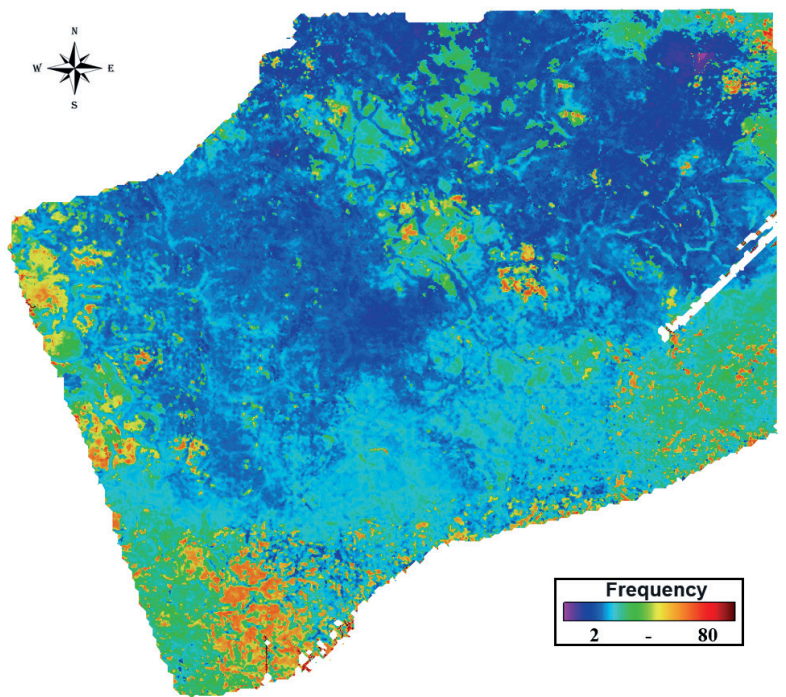

c) w紫

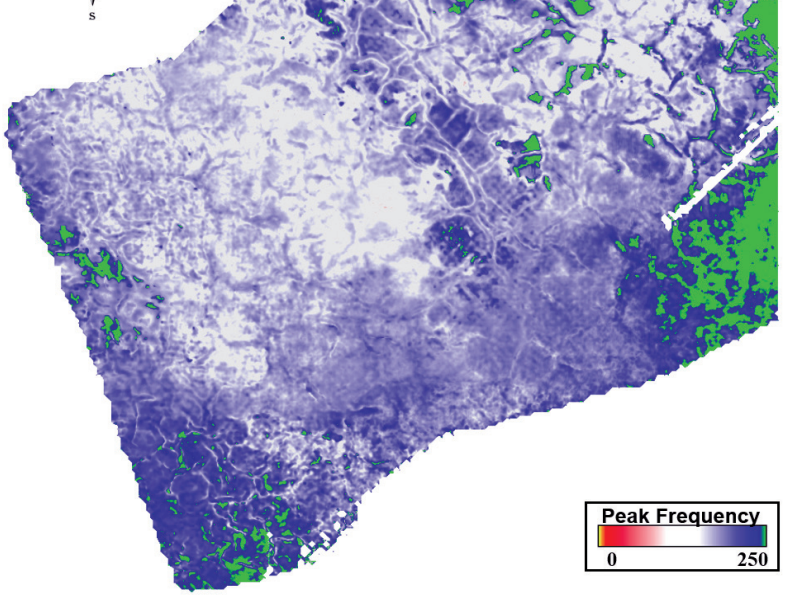

Figure 4: Plan view of (a) the instantaneous frequency peak, (b) the spectral magnitude of the $10 \mathrm{~Hz}$ component and (c) the spectral frequency peak, over the horizon Lower Glauconitic Zone top. a)

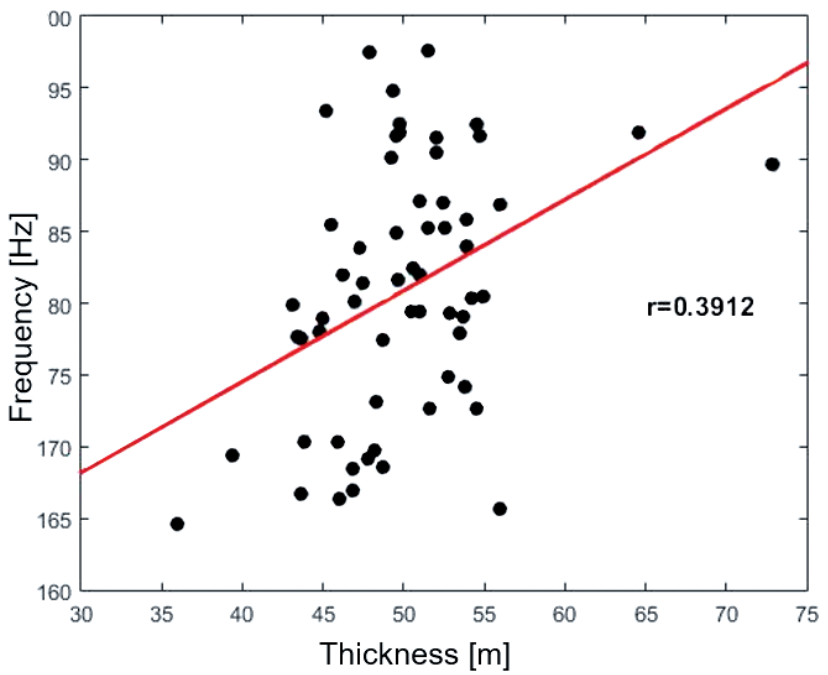

b)

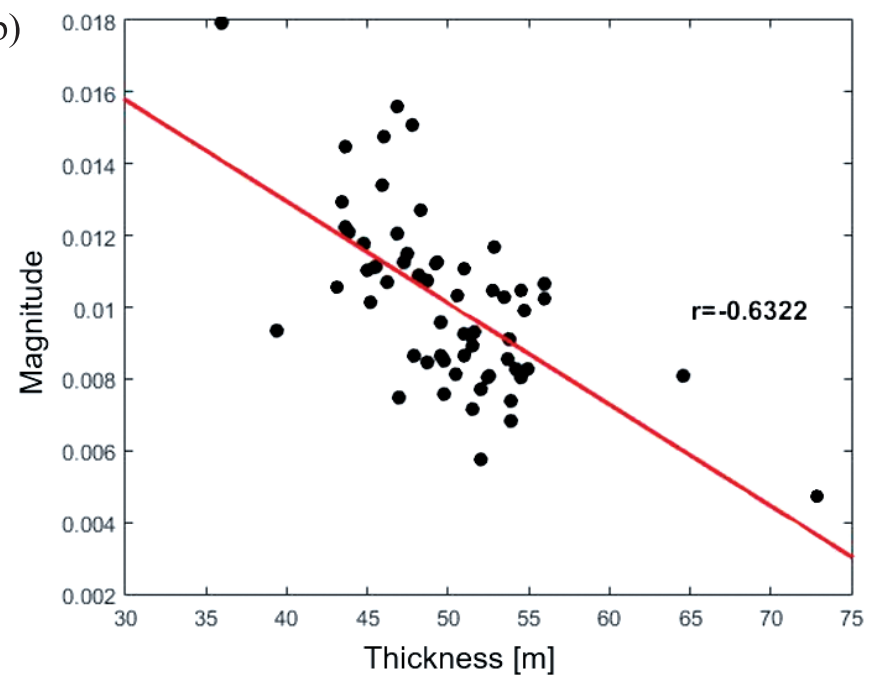

c)

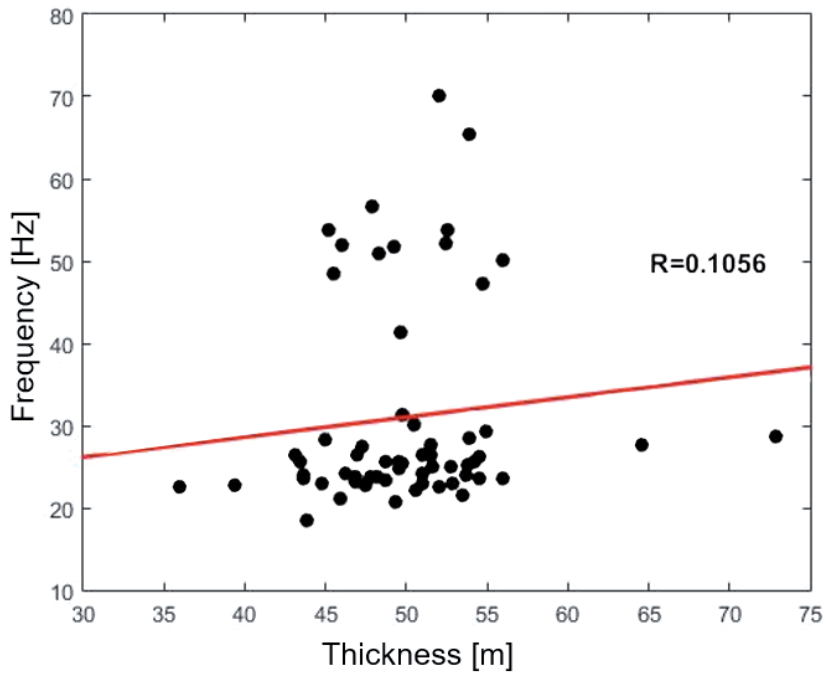

Figure 5: Scatter diagram between the attribute: (a) instantaneous frequency peak, (b) $10 \mathrm{~Hz}$ component and (c) spectral frequency peak and the thicknesses of the Lower Glauconite Zone, estimated from well logs. 
In Figure 4, the response of the evaluated attributes from the seismic data of the Lower Glauconitic Zone is presented. These results are compared with the thicknesses of the Lower Glauconitic Zone formation obtained from the well logs, presented in Figure 5.

As it is possible to appreciate in the scatter diagram comparing the attribute of instantaneous frequency peak to the thickness (see Figure 5a), a clear relationship is not observed, presenting a low correlation coefficient, and they are related in an inverse way to that established in Figure 2a. Similarly, the scatter diagram between the attribute of spectral frequency peak and the thickness of the stratum exhibits an almost null correlation coefficient and a high degree of dispersion in the data, as is shown in Figure 5c. The magnitude spectrum of the $10 \mathrm{~Hz}$ frequency component, on the other hand, is inversely related to the thickness with a good correlation coefficient $(r=-0.63)$, see Figure $5 b$.

\section{Discussion}

From the results obtained from the wedge models, it is possible to infer that the instantaneous frequency peak and spectral frequency peak attributes have a linear relationship with thickness only for the isolated layer wedge models, that is, only in the ideal cases where there are no interference effects from other rock layers. Therefore, they cannot be considered as reliable indicators when assessing the thickness of a formation. This is evidenced in the application of these attributes to the seismic data of the Lower Glauconitic Zone, as it is possible to observe in Figures $5 \mathrm{a}$ and $5 \mathrm{c}$, in which the dispersion diagrams between these attributes and the formation thickness estimated from well logs are presented. The diagrams show the poor relationship between instantaneous frequency peak, spectral frequency peak and estimated thickness.

On the other hand, the magnitude spectrum of a $10 \mathrm{~Hz}$ frequency component has a linear relationship with the thickness for the three wedge models, even evaluated with thick layers, which would allow us to quantify the entire thickness range. The application of this attribute to the seismic data of the Lower Glauconitic Zone shows a linear relationship with the thickness, presenting a good correlation coefficient $(\mathrm{r}=-0.63)$. But, as presented in Figure $2 b$, the relationship of this attribute to thickness is reversed by changing the elastic properties of the evaluated rock stratum. Therefore, it is not suitable for the mission of estimating the thickness of a thin layer of rock.

\section{Acknowledgements}

The authors would like to thank the management of ENAP Magallanes for allowing the publication of this document. And we would also like to thank the reviewers for their comments and in particular the editor for his advice on the previous and final versions.

\section{References}

Castagna, J.P., Sun, S. and Siegfried, R.W. (2003). Instantaneous spectral analysis: Detection of low-frequency shadows associated with hydrocarbons. The Leading Edge 22(2): 120-127

Chung, H.M. and Lawton, D.C. (1995). Amplitude responses of thin beds: Sinusoidal approximation versus Ricker approximation. Geophysics 60(1): 223-230

Hamlyn, W. (2014). Thin beds, tuning, and AVO. The Leading Edge 33(12):1394-1396

Kallweit, R.S. and Wood, L.C. (1982). The limits of resolution of zero-phase wavelets. Geophysics 47(7): 1035-1046

Liu, J. and Marfurt, K.J. (2006). Thin bed thickness prediction using peak instantaneous frequency. Society of Exploration Geophysicists SEG Technical Program Expanded Abstracts, 968-972

Marfurt, K.J. and Kirlin, R.L. (2001). Narrow-band spectral analysis and thin-bed tuning. Geophysics 66(4): 1274-1283

Partyka, G. (2005). Spectral decomposition. Society of Exploration Geophysicists distinguished lecturer

Partyka, G.A. (2001). Seismic thickness estimation: three approaches, pros and cons. Society of Exploration Geophysicists SEG Technical Program Expanded Abstracts, 503-506

Partyka, G., Gridley, J. and Lopez, J. (1999). Interpretational applications of spectral decomposition in reservoir characterization. The Leading Edge 18(3): 353-360

Robertson, J.D. and Nogami, H.H. (1984). Complex seismic trace analysis of thin beds. Geophysics 49(4): 344-352

Sun, L., Zheng, X., Li, J. and Shou, H. (2009). Thin-bed thickness calculation formula and its approximation using peak frequency. Applied Geophysics 6(3): 234-240

Taner, M.T., Koehler, F. and Sheri, R.E. (1979). Complex seismic trace analysis. Geophysics 44(6): 1041-1063

Widess, M.B. (1973). How thin is a thin bed?. Geophysics 38(6): 1176-1180

Zeng, H. (2010). Geologic signicance of anomalous instantaneous frequency. Geophysics 75(3): 23-30 